\title{
Effect of microstructure and mechanical properties on cutting force of different cast irons with similar tensile strength
}

\author{
*Jiang-zhuo Ren ${ }^{1}$, Zong-liang Li ${ }^{2}$, Yi Xiong ${ }^{2}$, Feng-jun Li ${ }^{3}$, Feng-zhang Ren ${ }^{2}$, and Alex A. Volinsky \\ 1. Faculty of Engineering, University of Alberta, Edmonton, T6G 1H9, CA \\ 2. School of Materials Science and Engineering, Henan University of Science and Technology, Luoyang 471023, China \\ 3. First Tractor Co. Ltd., Luoyang 471004, China \\ 4. Department of Mechanical Engineering, University of South Florida, Tampa, FL33620, USA
}

\begin{abstract}
Flake graphite iron, compacted graphite iron and spheroidal graphite iron with various tensile strengths were cast. They were selected and grouped according to roughly the same tensile strength, and then the main cutting force in each group was measured and compared. The microstructures of different cast irons were characterized. The relationship between the cutting force and microstructure was established. Results show that the graphite morphology in cast irons determines the strength. In order to obtain the same strength of the cast iron with sharply edged graphite, more or finer pearlite in the matrix is needed. Graphitic cast irons with high pearlite content and smaller pearlite interlamellar spacing have higher hardness. For the cast irons with different graphite morphologies, but almost the same tensile strength, the main cutting force is obviously different, along with the hardness. Harder cast irons have a greater cutting force, but the difference in cutting force is not proportional to hardness.
\end{abstract}

Key words: graphite cast irons; cutting force; tensile strength; microstructure

CLC numbers: TG143.2 Document code: A

Article ID: 1672-6421(2019)03-177-07

\begin{abstract}
A ccording to the 45 th World Casting Census, graphitic cast irons account for $73 \%$ of total metal castings in the world, and China is the top ranked producer of castings ${ }^{[1]}$. Graphitic cast irons fall in three categories: flake graphite iron (FGI), also known as gray cast iron; compacted graphite iron (CGI), also known as vermicular cast iron; and spheroidal graphite iron (SGI), also known as ductile cast iron. These graphitic cast irons differ in terms of graphite morphology. FGI is usually used to make machine tools and mechanical press components, engine cylinder blocks and heads, etc., due to its excellent castability, wear resistance, thermal conductivity and shock absorption ${ }^{[2]}$. SGI is used to make the crankshaft and cam of the internal combustion engine, etc., due to its high strength and toughness ${ }^{[3]}$. CGI is characterized by an intermediate graphite morphology between the flake and spheroidal graphite irons, and its mechanical properties are close to
\end{abstract}

\section{*Jiang-zhuo Ren}

Male, born in 1992, Ph. D student. Research interests: modern surface technology, materials machining technology.

E-mail: ren6@ualberta.ca

Received: 2018-11-02; Accepted: 2019-03-08
SGI, while its physical properties (thermal expansion, conductivity), and high-temperature properties (thermal fatigue, thermal shock), as well as castability, are close to FGI ${ }^{[4]}$. With such properties, CGI has found several applications in the automotive field, including its use in diesel high power engine cylinder blocks. Due to higher strength compared with FGI, CGI allows increasing the cylinder pressure, which results in higher energy production and fuel economy ${ }^{[5]}$.

General graphitic cast iron parts, such as an engine cylinder block and head, are usually machined using computer numerical control machines, or automated processing lines. Therefore machinability significantly affects machining efficiency and production cost. Thus, graphitic cast irons' machinability has attracted much attention and has been extensively studied and discussed. Cutting force, cutting heat, surface roughness and tool wear are generally used to evaluate a material's machinability ${ }^{[6,7]}$. Ren et al. ${ }^{[8]}$ studied the effects of inoculating addition on the FGI tool wear. Rosa et al. ${ }^{[9]}$ experimentally investigated the effects of Ti content on the tool wear, cutting force and surface roughness of CGI in the turning process. Zheng et al. ${ }^{[10,11]}$ studied the effects of inoculants and 
Sn on microstructure and cutting force of CGI. Nayyar et al. ${ }^{[12,13]}$ contrasted the machinability of FGI, CGI, and SGI with different strengths in terms of cutting temperature, cutting force, tool life, deformed chip thickness and contact length in different continuous machining operations. These research reports mainly focused on machinability of only one graphitic cast iron or the machinability comparison of different grades of graphitic cast iron with different strengths. However, the research on the machinability comparison of different graphitic cast irons with the same tensile strength level has not been reported.

In this paper, different graphitic cast irons (FGI, CGI, and SGI) with various tensile strength levels were cast. They were selected and grouped according to roughly the same tensile strength, and then the cutting forces in each group were compared. Meanwhile, the main factors affecting the cutting force, i.e. hardness and tensile strength, and the microstructure factors, including graphite morphology, pearlite content and pearlite interlamellar spacing, were investigated. The results offer guidance for selecting the processing route of different graphitic cast irons. One example is whether or not the cutting tool designed for cutting FGI can be used to cut CGI and SGI with a greater strength.

\section{Materials and experimental procedures}

\subsection{Materials and grouping}

FGI, CGI and SGI specimens with various tensile strength levels and dimensions of $\Phi 95 \mathrm{~mm} \times 350 \mathrm{~mm}$ were cast. The size of the gauge portion of the machined tensile specimens was $\Phi 14 \mathrm{~mm} \times 70 \mathrm{~mm}$ for CGI and SGI, and $\Phi 20 \mathrm{~mm} \times 60 \mathrm{~mm}$ for FGI, which were minimum sizes required by the National Standards of the P. R. China (GB/T 26655-2011, GB/T 13482009, GB/T 9439-2010). The tensile strength of each grade was the mean value of four tensile specimens. The samples for metallography and Brinell hardness tests were cut from the specimen whose tensile strength was the closest to the mean value of its group. Graphite morphology and content (percentage of the same graphite morphology), and pearlite content (area percentage) in the matrix were obtained by using an optical microscope (OLYMPUS PMG3) equipped with metallographic image analysis software. The pearlite interlamellar spacing was observed by the JSM-5610LV scanning electron microscope.

\subsection{Cutting force measurements}

Nine cast cutting specimens $(1 \mathrm{a}-4 \mathrm{~b}$ in Table 1$)$ were premachined to the $\Phi 89 \mathrm{~mm} \times 300 \mathrm{~mm}$ size. A general horizontal lathe was used with an ordinary mechanically clamped external cutting tool. Twin parallel octagonal ring dynamometer and dynamic signal measuring device with an analysis apparatus for signal acquisition and conversion were used to measure the main cutting force. The octagonal ring dynamometer was fixed on the lathe. The tool holder was fixed on the octagonal ring dynamometer and a cutting insert was fastened on the tool holder. A schematic diagram of the cutting force measurements is shown in Fig. 1. The system for the cutting force measurements and the corresponding process were described in Ref. [14].

All cutting force measurements were carried out using the same cutting process. The main shaft of the lathe rotated at 180 $\mathrm{rpm}$, the feeding rate was $0.294 \mathrm{~mm} \cdot \mathrm{rev}^{-1}$, the cutting depth was 2-5 $\mathrm{mm}$ (diameter reduction) and the initial cutting diameter was $89 \mathrm{~mm}$.

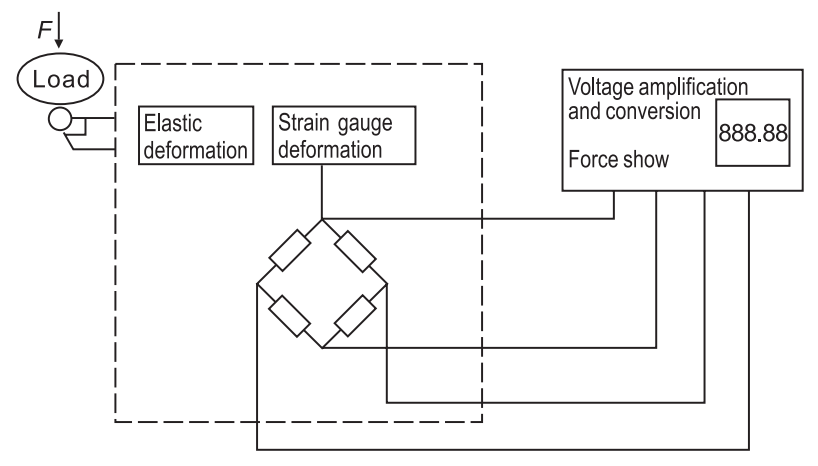

Fig. 1: Schematic diagram of cutting force easurements

\section{Results and analysis}

\subsection{Relationships between microstructure and strength}

The selection and grouping for FGI, CGI and SGI are shown in Table 1. Mechanical properties (tensile strength and Brinell hardness) and microstructural parameters (pearlite distribution, pearlite interlamellar spacing, graphite morphology and content) are also listed in Table 1. The graphite morphology and the matrix structure (pearlite distribution and morphology) of the tested FGI, CGI, and SGI are shown in Figs. 2-4. The microstructure parameters given in Table 1 are the quantification results for the corresponding microstructures in Figs. 2, 3 and 4.

The strength of graphitic cast irons depends mostly on the graphite morphology, pearlite distribution and pearlite interlamellar spacing. As shown in Table 1, in the same group with roughly the same tensile strength, the pearlite content in CGI is significantly lower than in FGI, and that in SGI is significantly lower than in CGI. This is because of the different graphite morphologies in different cast irons. Graphite with sharp edges significantly reduces the strength, and to obtain the same strength, more or finer pearlite is needed. The graphite morphology changes from flake to vermicular and further to spherical. The change of graphite morphology is as follows: First, graphite edges get rounded, which reduces the stress concentration at the interface between the graphite and the matrix. Second, the specific surface area of graphite decreases, which significantly reduces segmentation of the matrix. Comparing Samples 1a and $4 \mathrm{~b}$, their pearlite interlamellar spacing values are approximately the same, and the pearlite content of Sample 1a (FGI) is significantly higher than that in $4 \mathrm{~b}$ (SGI). However, the tensile strength of the FGI Sample $1 \mathrm{a}$ is much lower than that of the SGI Sample $4 \mathrm{~b}$, showing that the tensile strength of cast iron is mainly affected by the graphite morphology. 
Table 1: Grouping, mechanical properties, and microstructure of FGI, CGI, and SGI

\begin{tabular}{|c|c|c|c|c|c|c|c|c|c|}
\hline \multirow{3}{*}{$\begin{array}{c}\text { Group } \\
\text { Specimen }\end{array}$} & \multicolumn{2}{|c|}{1} & \multicolumn{3}{|c|}{2} & \multicolumn{2}{|c|}{3} & \multicolumn{2}{|c|}{4} \\
\hline & $1 \mathrm{a}$ & $1 \mathrm{~b}$ & $2 a$ & $2 \mathbf{b}$ & 2c & $3 a$ & $3 b$ & $4 a$ & $4 b$ \\
\hline & FGI & CGI & FGI & CGI & CGI & CGI & SGI & CGI & SGI \\
\hline Tensile strength ( $\mathrm{MPa})$ & 327 & 330 & 347 & 347 & 354 & 429 & 453 & 524 & 525 \\
\hline Brinell hardness (HBS) & 232 & 139 & 250 & 159 & 162 & 222 & 161 & 238 & 181 \\
\hline Pearlite content (\%) & 95 & 35 & 98 & 15 & 45 & 95 & 5 & 75 & 20 \\
\hline $\begin{array}{c}\text { Pearlite interlamellar } \\
\text { spacing }(\mu \mathrm{m})\end{array}$ & 0.29 & 0.41 & 0.28 & 0.35 & 0.4 & 0.67 & 0.3 & 0.4 & 0.3 \\
\hline $\begin{array}{c}\text { Graphite morphology and } \\
\text { content }(\%)\end{array}$ & $\begin{array}{c}\text { Flake } \\
100\end{array}$ & $\begin{array}{l}\text { Vermicular } \\
\quad 90\end{array}$ & $\begin{array}{c}\text { Flake } \\
100\end{array}$ & $\begin{array}{l}\text { Vermicular } \\
\quad 60\end{array}$ & $\begin{array}{l}\text { Vermicular } \\
\quad 60\end{array}$ & $\begin{array}{l}\text { Vermicular } \\
70\end{array}$ & $\begin{array}{l}\text { Sphere } \\
90\end{array}$ & $\begin{array}{l}\text { Vermicular } \\
\quad 50\end{array}$ & $\begin{array}{l}\text { Sphere } \\
90\end{array}$ \\
\hline
\end{tabular}
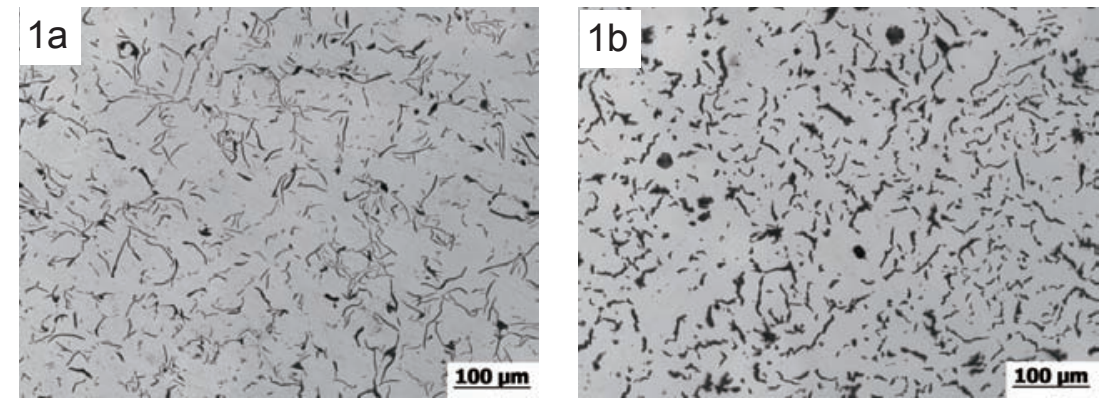
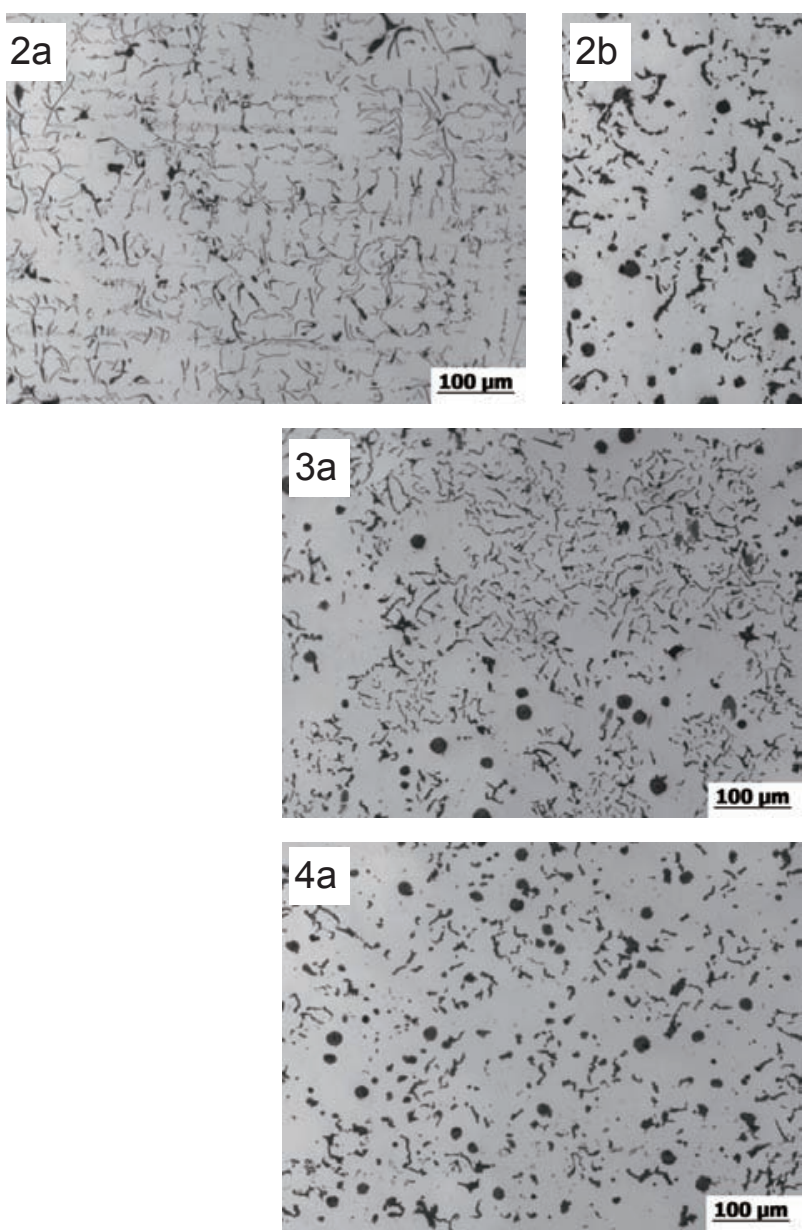
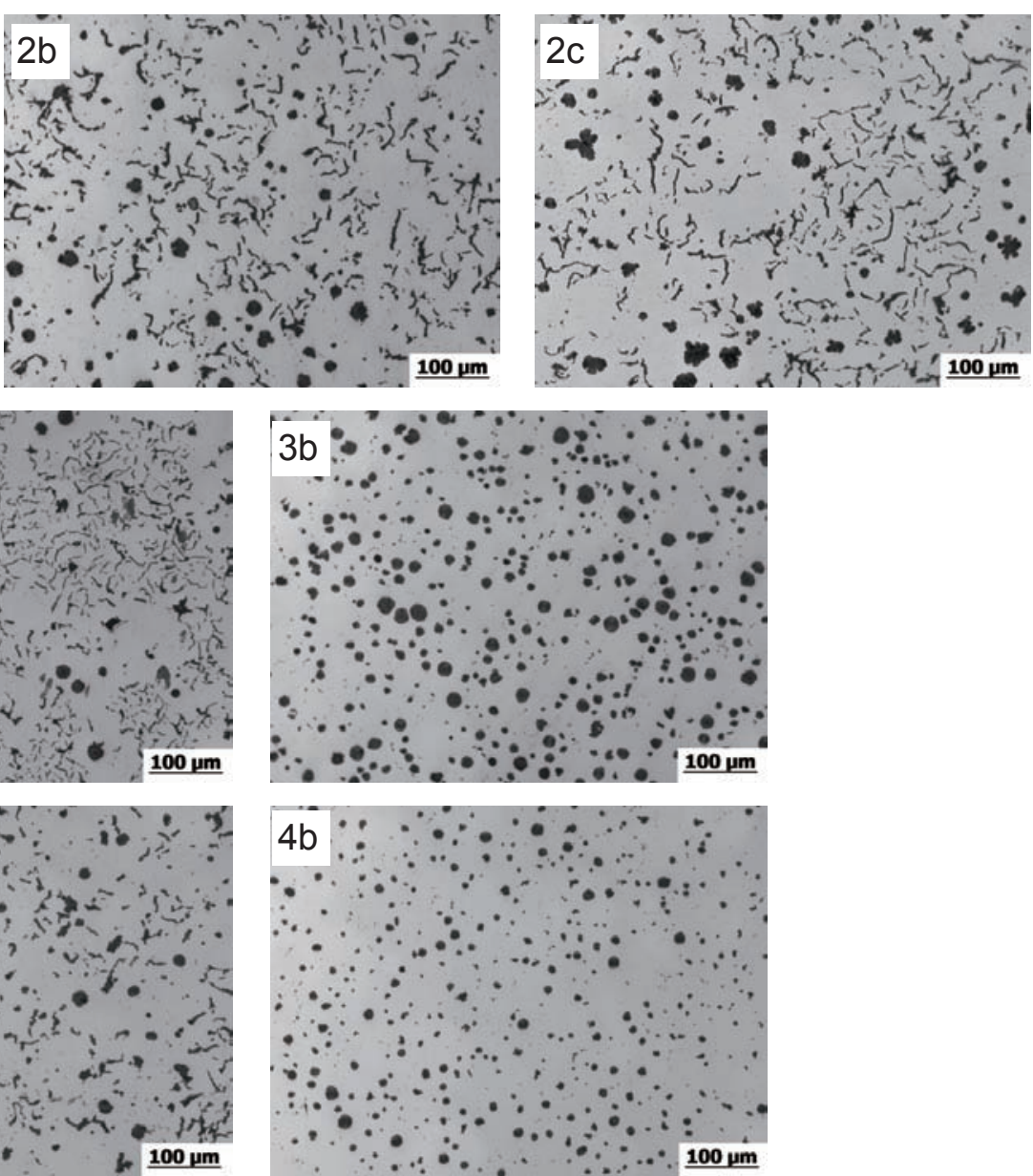

Fig. 2: Graphite morphologies of four groups of specimens in Table 1 (1a-4b are sequence numbers of specimens in Table 1) 

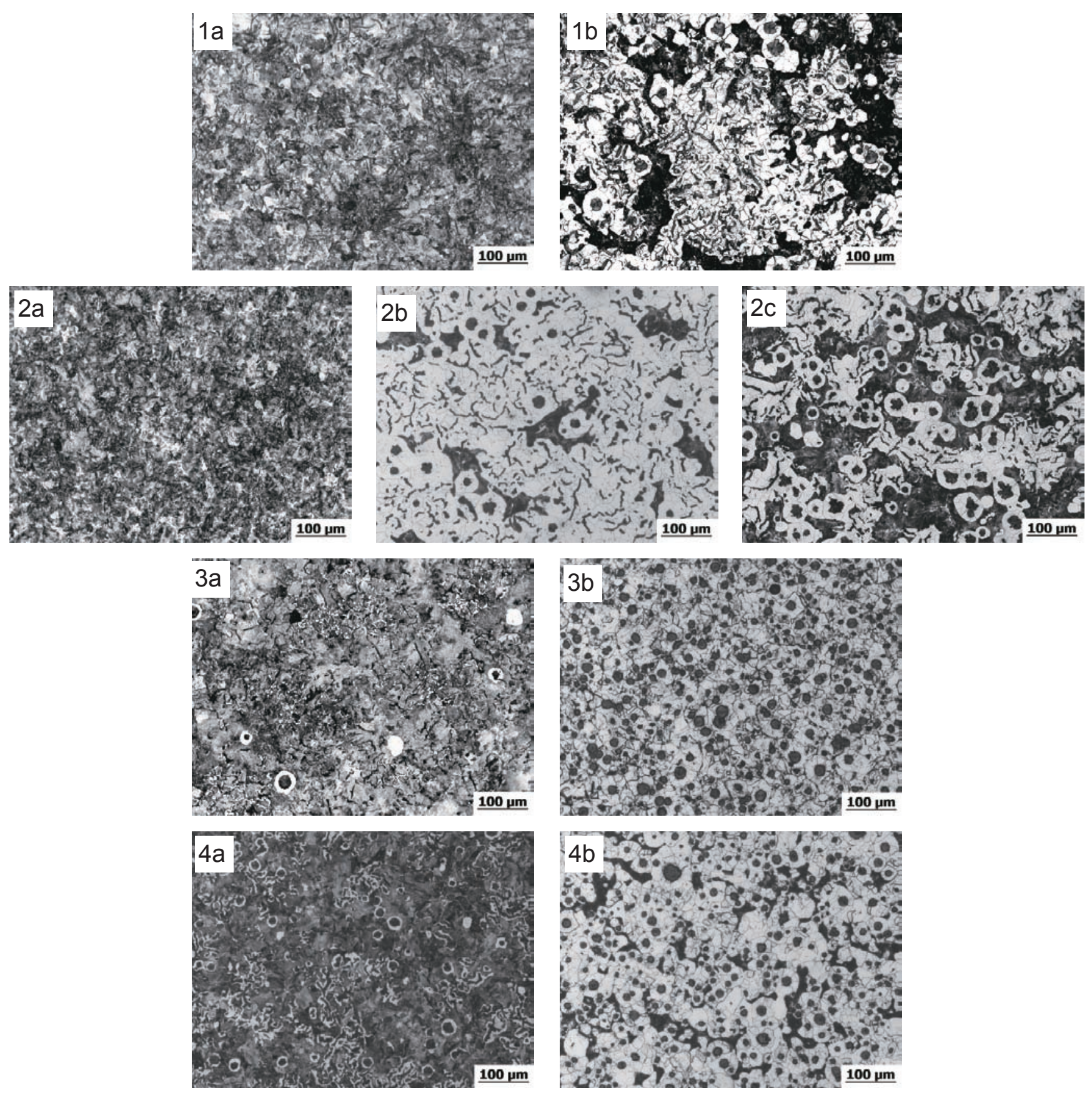

Fig. 3: Pearlite distribution of four groups in Table 1

Compared within the same graphitic cast iron category (i.e. same graphite morphology) in different groups, the graphite form and the graphite flake length of the FGI Samples 1a and 2a match the grade 4 of FGI (GB/T 7216-2009, the National Standards of the P. R. China). Flake graphite with random and homogeneous distribution has $0.12-0.25 \mathrm{~mm}$ size. The matrix is mainly pearlite and the pearlite interlamellar spacing is almost the same, but the pearlite content of the Sample 2a is slightly higher than that in 1a. The higher pearlite content results in both higher tensile strength and higher hardness of the Sample 2a compared with 1a. The nodularity of the SGI Samples $3 \mathrm{~b}$ and $4 \mathrm{~b}$ is $90 \%-95 \%$, and their graphite size is $0.015-0.030 \mathrm{~mm}$ and $\leqslant 0.015 \mathrm{~mm}$, respectively. The pearlite content of the Sample $4 b$ is obviously higher than that of $3 b$, but their pearlite interlamellar spacing values are about the same. The greater amount of pearlite results in higher strength and hardness of the Sample 4b than Sample 3b.

In summary, as shown in Table 1 for CGI, lower vermicularity (i.e. higher nodularity), higher pearlite content and smaller pearlite interlamellar spacing can result in higher tensile strength. For example, pearlite content and vermicularity value of Sample $1 \mathrm{~b}$ are obviously higher than those in $2 \mathrm{~b}$, while their pearlite interlamellar spacing values are approximately the same. The higher the pearlite content, the higher the strength should be, but the tensile strength of Sample $1 b$ is lower than that of $2 b$, which indicates that the vermicularity is the primary determinant of the tensile strength. 

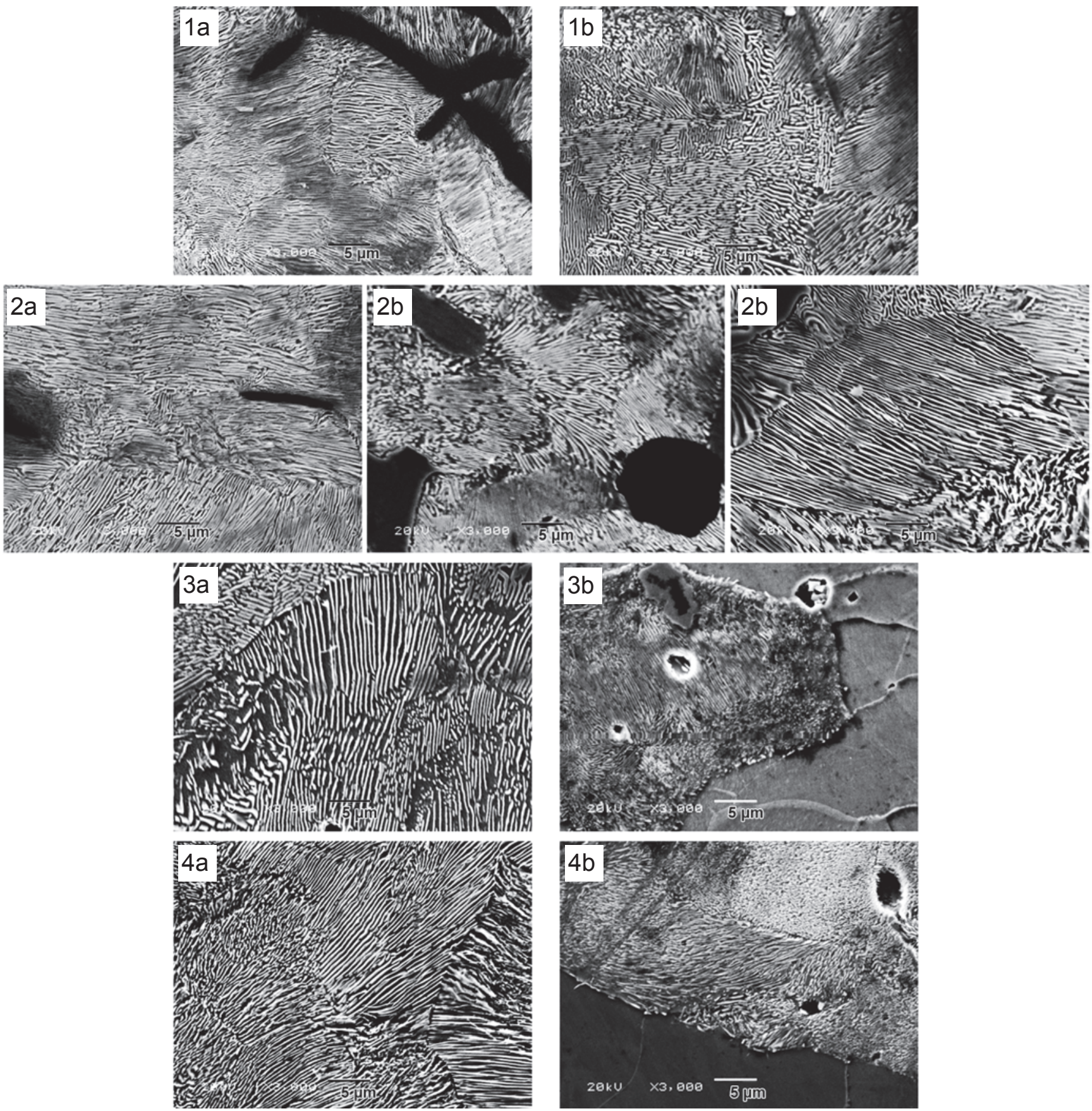

Fig. 4: Pearlite morphologies of four groups in Table 1

\subsection{Effects of microstructure on hardness}

Brinell hardness represents the resistance to plastic deformation. For graphitic cast irons, this depends on the graphitic morphology, content and size, pearlite content and pearlite interlamellar spacing. Brinell hardness of graphite is only about $3 \mathrm{HBS}^{[15]}$, which can be ignored compared with pearlite and ferrite. Graphite morphology has a strong influence on strength, but not on hardness ${ }^{[16]}$, and pearlite hardness is dramatically higher than ferrite. Thus, Brinell hardness of graphitic cast irons mainly depends on the pearlite content and pearlite interlamellar spacing. In Table 1, Brinell hardness of FGI is obviously higher than that for CGI, and CGI hardness is obviously higher than the SGI hardness in each group. The reason is the different pearlite contents in different irons. In Group 2, Samples 2b and 2c are both CGI, and obviously lower pearlite content of Sample $2 \mathrm{~b}$ should lead to lower hardness, but smaller pearlite interlamellar spacing of Sample $2 \mathrm{~b}$ increases the hardness. The combined influence of the two microstructure factors leads to almost the same hardness. Sample 1a from the 1st group and Sample 3a from Group 3 with the same pearlite content are compared. Slightly higher hardness of Sample 1a results from its smaller pearlite interlamellar spacing.

\subsection{Effects of hardness and microstructure on cutting force}

This work mainly focuses on the cutting force comparison of different graphite cast irons with a similar tensile strength. In 
each group, different graphite cast irons have almost the same tensile strength. The measured main cutting force for each group is shown in Fig. 5. In each group, although graphite cast irons with different graphite morphologies have almost the same tensile strength, their main cutting force values are obviously different, along with the hardness. In Group 2, the cutting forces of the two CGI samples with roughly the same hardness (159 HBS for $2 \mathrm{~b}$ and $162 \mathrm{HBS}$ for $2 \mathrm{c}$ ) are basically equal. In summary, cast irons with the higher hardness have a greater cutting force. In all 4 groups, the mean cutting force values at 4 cutting depths and the hardness values were compared in the same group. The corresponding percentage was calculated as $(b-a) / a \times 100 \%$, where $b$ is the corresponding value being compared to $a$. The different percentages of the cutting forces of every two cast irons in the same group (e.g. Group 2, 2b of the two CGI samples were used for comparison with the FGI Sample 2a) are determined to be 31.9\%, 35.6\%, $29.8 \%$ and $15.4 \%$, respectively, and the hardness percentage are $66.9 \%, 57.2 \%, 37.9 \%$, and $31.5 \%$, respectively. There is no clear proportionality between the cutting force and hardness percentages. This is because the hardness and the cutting force mean different things. The hardness represents
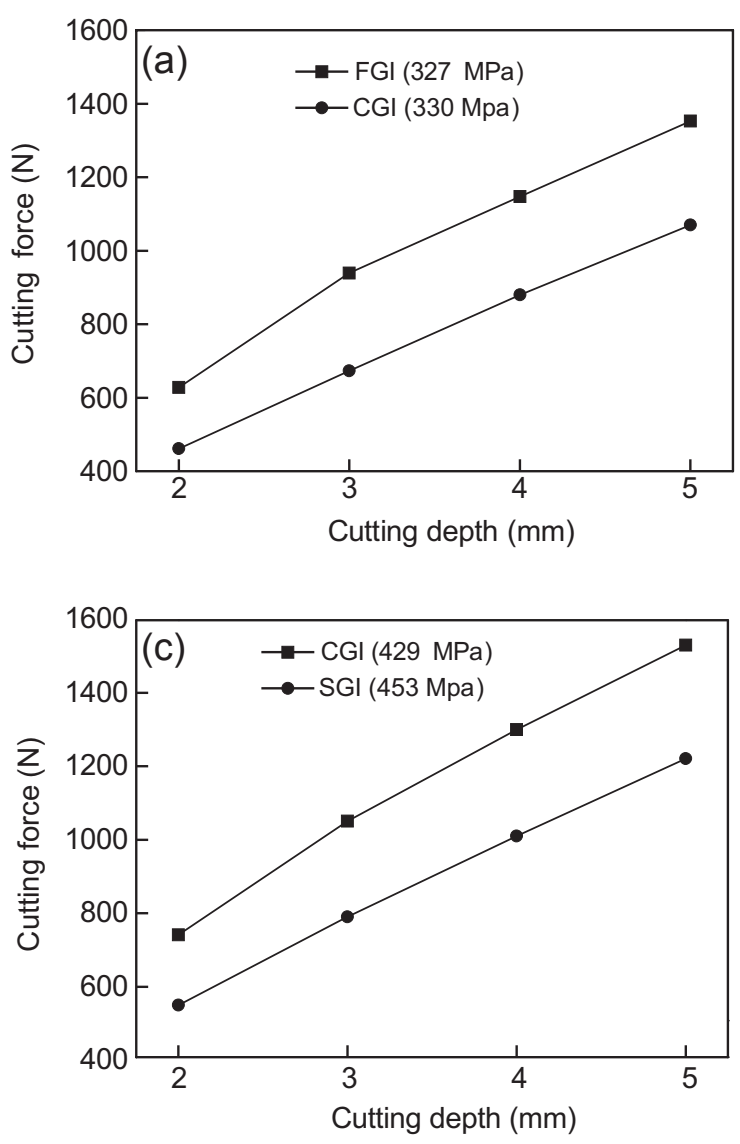

the resistance to plastic deformation, and for cast iron, it mainly depends on the pearlite content and interlamellar spacing. However, the cutting force reflects crack initiation and propagation resistance besides plastic deformation resistance, thus the relationship between the cutting force and microstructure is rather complicated. In terms of the crack initiation and propagation, round graphite edges reduce the stress concentration at the interface between the graphite and the matrix, leading to more difficult crack initiation. The pearlite with higher strength than ferrite makes it difficult for crack propagation from ferrite to pearlite, and smaller pearlite interlamellar spacing efficiently prevents crack propagation in pearlite, so the pearlite content and interlamellar spacing influence crack initiation and propagation, besides plastic deformation. Percentage of the cutting force change is smaller than that of the hardness in each group, which indicates that the influence of the pearlite content and interlamellar spacing on the cutting force is smaller than the hardness. However, based on Fig. 5 and microstructure Figs. 2-4, there is a strong positive correlation between the cutting force and the pearlite content, and an inverse correlation between the cutting force and the pearlite interlamellar spacing.
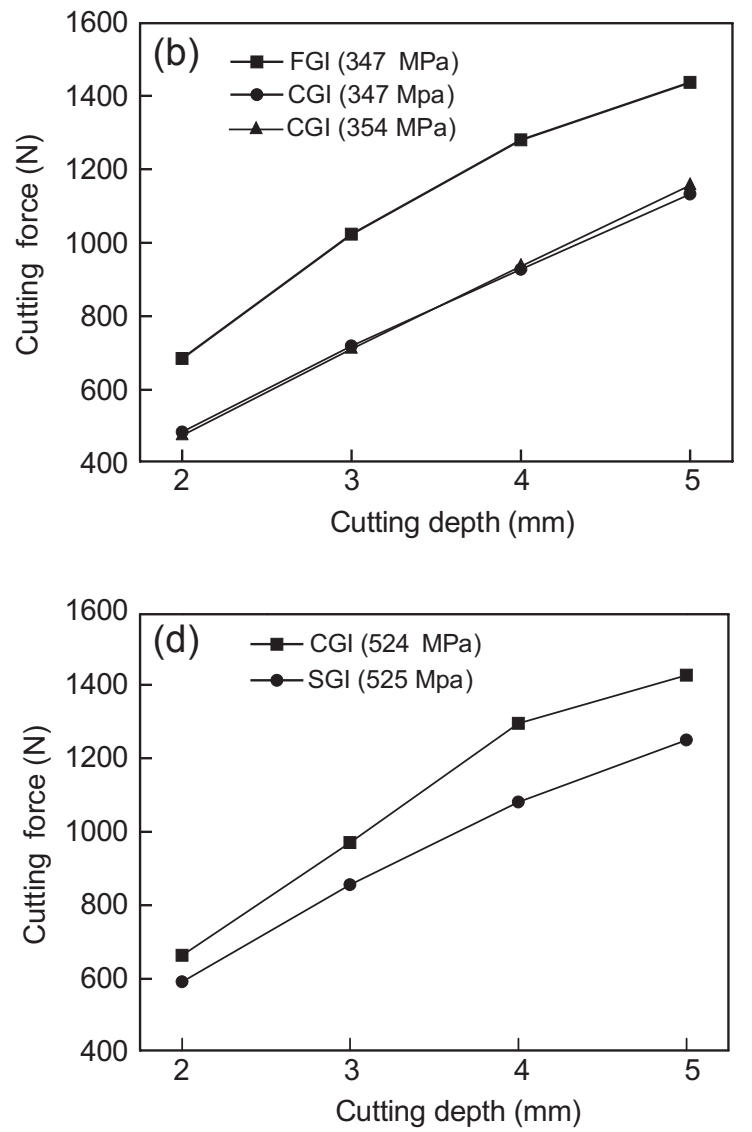

Fig. 5: Cutting force of four groups of specimens in Table 1 (a-d are sequentially 1 st -4 th groups)

\section{Conclusions}

(1) The tensile strength of graphitic cast irons is mainly affected by the graphite morphology. In order to obtain the same strength in cast iron with sharply edged graphite, more pearlite or finer pearlite in its matrix is needed.

(2) The pearlite content and interlamellar spacing determine the Brinell hardness of graphitic cast irons. Graphitic cast irons with high pearlite content and smaller pearlite interlamellar spacing have greater hardness. 
(3) For graphitic cast irons with different graphite morphologies, but with almost the same tensile strength, their main cutting force values are obviously different, along with the hardness. Cast irons with higher hardness have larger cutting force, but the cutting force is not proportional to hardness.

\section{References}

[1] A Modern Casting staff report - 45th census on World casting production. Modern Casting, 2011: 16-19.

[2] Casati R, Faccin R, Vedani M. Microstructural evolution and thermal fatigue resistance of grey cast iron. Fatigue Fract. Eng. 2018, 41: 99-110.

[3] Gonzaga R A. Influence of ferrite and pearlite content on mechanical properties of ductile cast irons. Mater. Sci. Eng. A, 2013, 567: 1-8.

[4] Stefanescu D M, Hummer R, Nechtelberger E. Compacted Graphite Iron; Metals Handbook, Vol. 15 - Casting, 9 ed. Materials Park: ASM International, 1990: 667-677.

[5] Heck M, Ortner H M, Flege S, et al. Analytical investigations concerning the wear behaviour of cutting tools used for the machining of compacted graphite iron and grey cast iron. Int. J. Refract. Met. H., 2007, 26: 197-206.

[6] Günay M, Korkut I, Aslan E, et al. Experimental investigation of the effect of cutting tool rake angle on main cutting force. J. Mater. Process. Tech., 2005, 166: 44-49.

[7] Ezugwu E O, Wang Z M. Titanium alloys and their machinabilitya review. J. Mater. Process. Tech., 1997, 68: 262-274.
[8] Ren F Z, Li F J, Liu W M, et al. Effect of inoculating addition on machinability of gray cast Iron. J. Rare Earth., 2009, 27: 294-299.

[9] Sílvia do Nascimento Rosa, Diniz A E, Andrade C L E, et al. Analysis of tool wear, surface roughness and cutting power in the turning process of compact graphite irons with different titanium content. J. Braz. Soc. Mech. Sci., 2010, 32: 234-240.

[10] Zheng B, Ren F Z, Li F J, et al. Effect of inoculants on microstructure and machinability of vermicular graphite iron. Foundry Tech., 2016, 37: 1659-1662. (In Chinese)

[11] Zheng B, Ren F Z, Li F J, et al. Effect of Sn on microstructure and machinability of vermicular graphite iron. Foundry, 2016, 65: 137-140. (In Chinese)

[12] Nayyar V, Kaminski J, Kinnander A, et al. An experimental investigation of machinability of graphitic cast iron grades; flake, compacted and spheroidal graphite iron in continuous machining operations. Procedia Cirp, 2012, 1: 488-493.

[13] Nayyar V, Grenmyr G, Kaminski J, et al. Machinability of compacted graphite iron (CGI) and flake graphite iron (FGI) with coated carbide. Int. J. Mach. Mach. Mater., 2013, 13: 67-90.

[14] Ren F Z, Zhang D W, Volinsky AA. Experimental investigation of the cutting force measurements in machinability evaluations of metals. J. Test. Eval., 2014, 42: 1541-1545.

[15] Qian L, Zhang H B, Zhao Y C, et al. Relationship between cutting machining properties of graphite-containing cast irons and their structures. Modern Cast Iron, 2005, 25: 17-20. (In Chinese)

[16] Li Z L, Ren F Z, Xiong Y, et al. Effect of vermicular agents, charges on microstructure, mechanical properties and cutting force of vermicular graphite iron. Trans. Mater. Heat Treat., 2017, 38: 96-101. (In Chinese) 